\title{
A Transferência Empresarial de Tecnologia para Países Subdesenvolvidos: um Caso Típico de Inadequação dos Meios aos Fins *
}

\author{
Fábio Konder Comparato \\ Professor Catedrático de Direito Comercial da \\ Faculdade de Direito da Universidade \\ de São Paulo.
}

O reconhecimento generalizado, neste último meio século, de que a tecnologia constitui um fator mais importante que o acúmulo de capitais, para o aumento da produtividade empresarial, deveria levar, naturalmente, a uma revalorização do sistema jurídico da propriedade industrial, considerado por tradição como dirigido ao desenvolvimento da técnica.

No entanto, os comentários críticos emanados de quase todos os países, nos últimos anos, traduzem um sentimento generalizado de crise do sistema dos privilégios industriais, ou seja, a consciência de que este padece, atualmente, de grave disfunção.

O que salta aos olhos, desde logo, é a inexistência de paralelismo entre o desenvolvimento da tecnologia industrial e o crescimento do número de invenções registradas nos países industrialmente mais evoluídos do planeta, isto é, nos centros mundiais de criação tecnológica. Nos Estados Unidos, por exemplo, o aumento do número de invenções depositadas no período de espantoso progresso técnico, que vai das vésperas da Segunda Guerra Mundial ao início da década de 60, foi de apenas 6\%. Mais recentemente, entre 1969 e 1978, o total de pedidos de privilégio industrial depositados em seis países altamente desenvolvidos - Alemanha Federal, Canadá, França, Holanda, Japão e Estados Unidos -, segundo as estatísticas divulgadas pela Organização Mundial da Propriedade Intelectual, teve um crescimento inferior a 10\%, com uma curva sensivelmente declinante a partir de 1973.

Em contrapartida, no mundo economicamente subdesenvolvido, tradicionalmente estéril na geração de tecnologia industrial, o aumento do número de invenções registradas ultrapassa o próprio crescimento do PIB. Num conjunto de 21 países africanos e asiáticos, escolhido

- Conferência pronunciada no II Seminário Nacional de Propriedade Industrial, no Rio de Janeiro, em 10-08-1982. 
pela OMPI, o total das invenções depositadas, no mesmo período de 1969 a 1978, aumentou em mais de 60\%. Obviamente, tais depósitos foram feitos, em sua esmagadora maioria, por estrangeiros $(85 \%$ dos pedidos depositados em 1978). Em nosso país, embora o número de depósitos de pedidos de patentes tenha permanecido relativamente estável nos últimos anos (em 1979, 11.496; em 1980, 11.312; em 1981, 11.351), quase três quartos desses depósitos são feitos por estrangeiros. Quanto à concessão de patentes no Brasil, em 1981, nada menos que 91,8\% do total pertencem a estrangeiros.

$\mathrm{Na}$ verdade, a importância reduzida do sistema de privilégios industrias, como modo de transferência de tecnologia para os países subdesenvolvidos, já não escapa a nenhum observador atento. Em 1972, calculou-se que a parte dos privilégios, de modo geral, na totalidade da tecnologia transferida dos países ricos para os povos industrialmente mais atrasados não supera $5 \%$; cifra que não deve, evidentemente, ser tida como precisa, dada a enorme discutibilidade do cálculo, mas que representa, sem dúvida, uma aproximação sugestiva da realidade.

Não é difícil atinar com as razões do fato. Em relatório publicado em 1964 por recomendação da Assembléia Geral das Nações Unidas, mediante iniciativa do nosso país, o Secretário Geral da ONU afirmou que "as patentes exercem uma função restrita na transferência dos conhecimentos técnicos, em razão de os conhecimentos técnicos, objeto de patentes, não serem senão uma parte dos que devem ser passados aos países subdesenvolvidos e dos que o são, efetivamente. Assim é, notadamente, porque grande parte dos conhecimentos técnicos de que necessitam tais países não estão entre os mais avançados, e são estes os únicos patenteados. Ademais, os países subdesenvolvidos carecem a tal ponto de conhecimentos técnicos gerais e de experiência gerencial que os conhecimentos patenteados são geralmente insuficientes, por si sós, para introduzir novos produtos, e novos processos nesses países". $\mathrm{E}$ prosseguindo nessa linha de raciocínio, declarou esse mesmo relatório: "No tocante aos estrangeiros titulares de patentes (em países subdesenvolvidos), é de todo excepcional, sobretudo nos países mais atrasados, que uma empresa nacional tenha condições de fabricar o produto ou de utilizar o processo, garantido por uma patente, sem recorrer à colaboração técnica, administrativa ou financeira do titular estrangeiro da patente, ou a outras fontes estrangeiras. Assim ocorre, principalmente, porque a aplicação de invenções novas e sua utilização prática somente é possivel quando já se possuem os conhecimentos técnicos não patenteados, pressuposto pelas fórmulas, processos, planos, segredos de fabricação etc." (E/3.861/Rev. 1 , Le rôle des brevets dans le transfert des camnaissances techniques aux pays en voie de développement).

Acresça-se a isto que os grandes centros empresariais e militares do mundo já tomaram consciência, há algumas décadas, de que o fator determinante do crescimento econômico e da supremacia bélica não é, exatamente, como pensavam os teóricos do século passado, a 
acumulação de capital e a extensão territorial, mas a acumulação ae saber e tecnologia. A ciência e a técnica são, hoje, os instrumentos decisivos do imperialismo econômico e militar, e sua preservação depende, em boa parte, da aplicação de uma severa política de segredo e reserva. Ora, o sistema dos privilégios industriais, implicando sempre uma publicação do invento a ser registrado, é incompatível com essa política de acumulação reservada de conhecimentos técnicos.

Resulta daí, em boa medida, a importância crescente assumida pelo know-how industrial e mesmo comercial, relativamente às patentes de invenção ou modelos de utilidade, como forma de transferência de tecnologia. Sem dúvida, de um lado, a complexidade cada vez maior dos dados técnicos faz aumentar, proporcionalmente, as exigências de capacidade gerencial e experiência de fabricação, para a utilização de patentes. Mas, também, de outro lado, a possibilidade de manter em segredo os novos inventos, somente revelando a terceiros escolhidos o que pode ser divulgado sem dano para a manutenção do poder econômico da empresa no mercado, leva à multiplicação dos contratos de prestação de know-how, ao invés do depósito de patentes e da licença de sua utilização.

Todos esses condicionamentos parecem estar na origem da reduzida importância que assume, ainda hoje, o comércio mundial de tecnologia. Segundo a Conferência das Nações Unidas para o Comércio e o Desenvolvimento (TD/B/C.6/55: Legislation and Regulations on Technology Transfer: Empirical Analysis of their Effects in Selected Countries), a receita de 6 dos principais países industrializados (Alemanha Federal, Estados Unidos, França, Grã-Bretanha, Holanda e Japão), com a exportação de tecnologia em 1976, montou a cerca de 7 bilhões de dólares, ou seja, menos de $1 \%$ do total das exportações mundiais no ano anterior ( 880 bilhões de dólares). Daquele total de royalties, apenas $17 \%$ provieram de países subdesenvolvidos. Quando se aproximam esses números do fato que $40 \%$ do total das exportações de bens do Ocidente industrializado dirige-se para os países subdesenvolvidos, tem-se mais uma medida para aferir a reduzida importância da transferência de tecnologia para essas nações.

Retomando agora, depois de tantos outros, a análise do sistema dos privilégios industriais e dos contratos de prestação de know-how, em função das carências tecnológicas dos países subindustrializados, gostaria de reapreciar, numa primeira parte, o fundamento teórico desses privilégios, a fim de ensaiar, numa segunda parte, a busca de soluções aos problemas suscitados, de modo a verificar até que ponto é possível tornar menos ineficiente o fluxo de conhecimentos técnicos para o Terceiro Mundo, por via empresarial.

I

\section{O Fundamento Teórico dos Privilégios Industriais}

A função ideológica da teoria jurídica tem sido tantas vezes denunciada, que me considero dispensado de repisar o óbvio. Por isso 
mesmo, não surpreenderei certamente ninguém ao tentar apontar as ideologias subjacentes à concepção teórica dos privilégios industriais.

Duas tradições, como sabido, concorrem na explicação racional desse instituto: a da propriedade, que remonta à lei revolucionária francesa de 7 de janeiro de 1791 e ao Patent Act norte-americano de 1790, e a tradição inglesa de monopólio legal de direito privado, firmada desde o Statute of Monopolies de 1624.

$\mathrm{Na}$ verdade, ambas essas concepções visam ao mesmo alvo: impedir a invasão arbitrária do Poder Público na exploração dos inventos industriais, com a concessão de privilégios vitalícios ou perpétuos a determinadas famílias.

Para os revolucionários franceses de fins do século XVIIII, ce serait attaquer les droits de l'homme dans leur essence que de ne pas regarder une découverte industrielle comme la propriété de son inventeur (Lei de 7 de janeiro de 1791, preâmbulo). Essa declaração solene teve eco na conferência internacional de Paris, de 1878, cujos trabalhos redundariam, cinco anos depois, na convenção criadora da União para a proteção da propriedade industrial. Os representantes diplomáticos fizeram questão de declarar, então, que les droits des inventeurs et des créateurs industriels sur leur propre travail, ( ..) sont des droits de propriété. La loi promulguée par chaque nation ne crée pas ces droits, mais se borne à les réglementer.

Mas a aplicação da noção de propriedade aos inventos industriais não é logicamente sustentável.

$\mathrm{O}$ direito de propriedade tem por objeto um bem, material ou imaterial, cuja fruição não depende do desenvolvimento de uma atividade pelo proprietário. Trata-se de uma situação estática, redutivel a relação de pura pertinência, com ou sem posse direta do bem. No invento industrial, diferentemente, é preciso distinguir a idéia, do seu suporte material (coisa tangivel ou sensivel, energia). Aqui, objeto da proteção jurídica não é, apenas, a relação de autoria ou criação da idéia (o chamado "direito moral", nas obras literárias, científicas ou artísticas), mas também e sobretudo a reprodutibilidade do seu suporte concreto pela exploração empresarial. No primeiro caso há, portanto, nitidamente, um habere; no segundo, um facere. A mera comunicação da idéia inventiva não ofende o direito exclusivo do inventor, desde que se não conteste a relação de paternidade, que não tem conteúdo patrimonial. Tampouco viola essa exclusividade a simples posse de um ou alguns dos objetos fabricados a partir da invenção, desde que não se tente reproduzir indevidamente o invento, ou ajudar outrem a escoar os objetos indevidamente fabricados.

A função declaratória da lei limita-se, por conseguinte, ao fato jurídico da invenção, enquanto idéia nova; não à exclusividade de sua exploração industrial, que representa sempre um posterius relativa- 
mente a esse fato, e que depende da organização de uma atividade técnica por si ou por outrem, para o aproveitamento da idéia.

Por outro lado, a concepção inglesa do monopólio legal de direito privado apresenta os privilégios industriais como exceçōes ao princípio da livre iniciativa empresarial. Sucede que a liberdade de concorrência pressupõe a multiplicidade de agentes, em situação de igualdade no mercado. A partir do momento em que se instaura um mecanismo de acumulação do poder econômico em favor de um ou alguns agentes, apenas, a livre iniciativa se torna mera ficção e a livre concorrência um mito justificador do status quo. Ora, em se tratando de um bem de capital, cuja posse é decisiva para o sucesso empresarial e o desenvolvimento econômico, como é a tecnologia sua repartição forçosamente desigual entre os agentes econômicos é o fator que mais rapidamente conduz à situação de abuso de posição dominante nos mercados. A sanção legal à exclusividade de exploração empresarial, por parte dos detentores dos conhecimentos técnicos, não constitui, assim, mera exceção ao principio da livre concorrência, mas a confirmação jurídica de uma desigualdade de fato já existente.

Colhe-se aí a essência dessa disfunção do regime jurídico dos privilégios industriais, a que aludi acima. A justificação funcional do instituto foi, originalmente, o incentivo à atividade inventiva como fator de progresso material da coletividade. Até o presente século, essa atividade inventiva tinha existência autônoma, não integrada à organização empresarial. Atente-se para qualquer das invenções industriais anteriores à Primeira Guerra Mundial - a utilização idealizada por Watt da teoria do calor latente na criação da câmara de condensação separada dos motores a vapor, ou a exploração do eletromagnetismo por Marconi para a criação da radiotelegrafia, por exemplo - e ver-se-á, de plano, que o inventor nunca fora homem de empresa. Mas corra-se a lista das grandes invenções industriais do século XX e ter-se-á grande dificuldade em encontrar algum que tenha medrado fora do âmbito empresarial. Os trabalhos de Carother, que levaram à fabricação do nylon, desenvolveram-se na Du Pont de Nemours; as pesquisas de Shockley, responsáveis pela invenção do transistor, foram todas feitas na Bell Telephone. $\mathrm{E}$ assim por diante.

O fato novo, responsável pela grande transformação da atividade produtiva, na era contemporânea, é justamente a organização e a programação do progresso tecnológico, como função da empresa, pública ou privada. Mesmo quando a pesquisa científica é patrocinada e custeada pelo Estado para fins políticos - como sucede na indústria bélica - ela acaba se moldando às exigências do funcionamento das empresas. Tanto mais que, atualmente, a simples demonstração, pela pesquisa, da solução prática de determinado problema não é bastante para seu aproveitamento industrial, sem um trabalho mais ou menos longo de desenvolvimento da invenção para fins de sua exploração empresarial. Para voltar, ainda uma vez, ao exemplo da máquina a vapor, a idéia de Watt, do condensador separado, estava perfeita e acabada desde 1765; mas foi preciso aguardar vários anos, até que 
a sociedade com os capitalistas Roebuck e Boulton propiciasse os recursos necessários ao desenvolvimento industrial do invento.

O laboratório de pesquisas industriais não tem mais de um século de existência: ele foi criado na indústria química alemã por volta de 1880. Ainda em 1895, só havia um laboratório industrial nos Estados Unidos: o de Thomas Edison. Hoje, toda empresa industrial de porte mantém um departamento de pesquisa e desenvolvimento e nele investe somas consideráveis. Somente a I.B.M. despende, por ano, um bilhão e meio de dólares em pesquisas e desenvolvimento. O privilégio deixou, por conseguinte, de ser um prêmio ao inventor isolado, para se transformar em garantia da amortização dos investimentos empresariais no setor de pesquisa e desenvolvimento. Garantia sem dúvida justicável, à luz da lógica empresarial, mas que acaba redundando, forçosamente, na consolidação do poder econômico, dentro e fora dos espaços nacionais.

Aliás, a consideração exclusiva dos aspectos concorrenciais, no regime das patentes, acarreta a negação prática de sua função social, de estímulo às invenções de interesse para a coletividade. A utilização social do produto ou processo inventado torna-se de consideração secundária, na economia do sistema. O que importa é a regulação da concorrência, regulação essa que, como se assinalou, tende a reforçar e não a tenuar os desequilíbrios de poder e influência no mercado.

Ora, a análise crítica necessária à reconstrução do instituto há de partir da função que ele deve exercer na sociedade.

Desde os primórdios do direito industrial, sempre se considerou que o inventor tinha o munus público de instruir os interessados na utilização da nova idéia de fabricação. Não foi, por isso, simples coincidência se o Statute of Monopolies de 1624 fixou a duração do privilégio em 14 ou 21 anos, isto é, sempre em múltiplo do período de aprendizagem na guildas ou corporações de ofício, que era de 7 anos.

$O$ direito exclusivo de exploração industrial não podia, nessas condições, ser considerado como resultado de simples ato declaratório do governo, ou reconhecimento de um direito de propriedade. Sempre se tratou de um direito-função, de um poder-dever. Daí por que a publicidade obrigatória do invento depositado não constitui, tão-só, uma advertência aos terceiros, para que impugnem o depósito do pedido, ou se abstenham de utilizar a idéia do inventor, mas representa também a informação indispensável ao aperfeiçoamento do nível técnico da coletividade, no campo industrial do produto ou processo inventado.

Pois é essa função formadora e instrutora da coletividade que deve, doravante, ser posta em relevo, no regime jurídico dos privilégios industriais, e não o simples interesse na amortização de investimentos. Não que esta última consideração seja desprezível, mas ela deve subordinar-se à consecução do interesse maior da coletividade e, de qualquer modo, não precisa se realizar, necessariamente, por via de uma garantia de mercado. 
A concessão da exclusividade na exploração industrial do invento aparece, nessa perspectiva, como uma espécie de prêmio ou incentivo legal à divulgação da nova idéia industrial; um tertium genus, entre o reconhecimento do "direito natural" de propriedade do inventor e a divulgação compulsória do invento, sem contrapartida. Essa última solução, aliás, além de injusta, seria de mui discutível efetividade. Injusta, porque o exercício pelo particular de um munus público exige adequada compensação de seu sacrifício; de efetividade duvidosa, pois - Direito ainda não conseguiu criar mecanismos apropriados de execução específica, nas obrigações de fazer, cuja prestação apresenta alta complexidade, como é o caso da tecnologia industrial.

Em suma, a exploração dos inventos industriais no âmbito de um direito promocional ou premial - e não como propriedade ou monopólio privados - parece, hoje, melhor atender às exigências e necessidades de um mundo fundamentalmente desequilibrado, em sua organização social e econômica.

\section{II}

\section{Proposta de Aperfeiçoamento do Regime Jurídico de Transferência Empresarial de Tecnologia}

Convém examinar, distintamente, a problemática das invenções registráveis e a dos contratos de prestação tecnológica (know-how), à luz das considerações que acabam de ser feitas.

\section{A —Inventos Industriais:}

Qualquer tentativa de reformulação do regime jurídico das invenções industriais, no âmbito nacional, é obstada pela estrutura internacional da exploração econômica nelas fundada. Justamente pelo fato de que a capacidade inventiva é, sempre mais, função do investimento em pesquisa e desenvolvimento, e de que esse investimento é feito, em sua maior parte, por empresas multinacionais, ou pelo próprio Estado para fortalecimento das exportações, as soluções jurídicas para o problema da exploração de invenções industriais devem ser também de cunho internacional.

A esse respeito, desponta de todos os lados do mundo subdesenvolvido a insatisfação quanto às regras fundamentais da Convenção de Paris, de 1883, que ainda é o direito internacional básico na matéria. Dois dos princípios por ela consagrados, sobretudo, têm sido mais largamente criticados: o do tratamento nacional e o da independência dos registros nacionais de invenções.

$\mathrm{O}$ princípio do tratamento nacional corresponde à aplicação da idéia de igualdade dos agentes econômicos, nos mercados nacionais. Mas se, de fato, a proclamação de que todos são iguais perante a lei tinha sentido revolucionário, no século XVIII, como forma de abolição de monopólios e regalias pessoais, a sua manutenção em países 
de economia totalmente desequilibrada, em que a acumulação de poder tecnológico é sempre feita nas empresas de controle estrangeiro, corresponde à consolidação jurídica dessa desigualdade de fato.

Algo de semelhante ocorre com o princípio da independência internacional dos registros de invenção, que é, a rigor, um corolário do tratamento nacional. Como a maioria absoluta das patentes registradas em paises subdesenvolvidos é de origem estrangeira, o depósito no estrangeiro precede o depósito nesses países. Se pelo exame mais rigoroso e competente do pedido, as autoridades estrangeiras denegam o registro por razões de fundo, por que haveria de ser deferido ou mantido o registro nos demais países? G. Finniss, presidente honorário do conselho de administração e diretor geral do Instituto Internacional de Patentes, observou que, até os anos 70, o mundo estava dividido em dois campos, no tocante ao registro de patentes: o dos países em que esse registro se fazia por simples depósito ou exame formal do pedido e o dos que procediam a um exame rigoroso das condições de fundo dos pedidos depositados. No primeiro campo, encontravam-se alguns países europeus (França, Suíça, Itália, Espanha, Portugal, Bélgica, Luxemburgo) e a generalidade dos subdesenvolvidos (estes, em grande parte, por falta de aparelhamento dos serviços administrativos de exame das patentes). No segundo campo situavam-se os Estados Unidos, a Grã-Bretanha e a Alemanha Federal. As empresas destes últimos paises freqüentemente obtinham, no estrangeiro, registros de patentes que lhes eram denegados em seus próprios países. Hoje, com a criação de serviços regionais de exame de patentes (como na África) e com o recurso mais freqüente ao próprio Instituto Internacional de Patentes, essa dualidade de regimes tornou-se menos acusada. Mas uma certa incongruência ainda persiste (Les brevets et l'expansion économique, in Mélanges en l'Honneur de Daniel Bastian, t.2, Paris, pp. 223 ss.).

No Brasil, o artigo $4^{\circ}$ da Lei $n^{\circ} 4.137$, de 1962, dispõe que "será automaticamente cassada a patente concedida pelo Departamento Nacional da Propriedade Industrial (antecessor do atual INPI), desde que feita a prova de já haver sido concedida e caducado em nação que mantenha acordos sobre a matéria com o Brasil". Embora tecnicamente contrário às normas da Convenção da União de Paris, esse dispositivo foi declarado em vigor pelo Conselho Administrativo de Defesa Econômica (processo administrativo no 4, decisão de 22-10-68).

O nosso Código da Propriedade Industrial exige, nos casos de reivindicação da propriedade de depósitos feitos no estrangeiro, que o requerente indique o número, a data, o título, o relatório descritivo e as reivindicações relativas ao depósito ou à patente no estrangeiro (art. 17). A recente lei-modelo da OMPI sobre invenções para países subdesenvolvidos vai mais longe, exigindo que o requerente apresente, a pedido dos serviços nacionais de patentes, informações completas sobre depósitos ou registros no estrangeiro, haja ou não reivindicação de prioridade (art. 128). 
Tudo indica, por conseguinte, que o rigor do principio da independência dos registros nacionais de invenções tende a ser atenuado.

$\hat{\mathbf{E}}$ possivel que o veto dos países industrializados à revisão da Convenção de Paris conduza as negociaçōes a um impasse. Nessa hipótese, os Estados subdesenvolvidos deveriam encarar seriamente a possibilidade de substituir o sistema da União de Paris por acordos regionais de uniformização legislativa, como o celebrado pelos países do Pacto Andino (Acordo de Cartagena, de 1969).

Essa harmonização legislativa, nos países subdesenvolvidos deveria prever, antes de mais, alternativas para o patenteamento de invenções. Os exemplos e precedentes não faltam.

As nações do bloco comunista conhecem, há vários anos, os chamados "certificados de atribuição", que não outorgam um direito de exploração ao inventor, mas the conferem uma remuneração, correspondente às economias que seu invento propiciou à indústria nacional. De acordo com o sistema econômico desses países, somente os organismos estatais podem explorar tais invenções.

O projeto oficial de revisão da Convenção de Paris admite em seu artigo $1^{\text {o }}$ a expedição, além das patentes, de "certificados de autoria de invenções", que poderiam ser: a) "um título cujo detentor tem direito a uma remuneração e outros direitos e privilégios, em virtude da legislação nacional do país que o expediu, e que confere ao Estado os direitos de exploração da invenção, ou submete essa exploração por terceiros à autorização de uma autoridade governamental", ou então, b) "um título cujo detentor tem o direito de explorar a invenção e obter de outras pessoas uma remuneração pela sua utilização de invenção aprovada pela autoridade nacional, mas sem o direito de excluir outras pessoas da utilização das invenções".

A Decisão 85 dos países do Grupo Andino prevê que o titular de uma patente gozaria, durante os primeiros 5 anos do registro, de um direito exclusivo de exploração; durante os 5 anos seguintes, qualquer interessado poderia se utilizar da patente, pagando ao titular as regalias correspondentes. Ou seja, no segundo período de duração da patente, o seu titular não teria direito exclusivo à exploração.

$\mathrm{Na}$ Colômbia, no México e nas Filipinas, a legislação nacional criou licenças compulsórias de utilização de patentes, indepedentemente de não-uso pelo titular, desde que fundadas tais licenças em razões de interesse público relevante.

$\mathrm{Na}$ lei-modelo sobre invenções para países subdesenvolvidos, elaborada pela OMPI, prevê-se, igualmente, a concessão de licenças compulsórias de utilização de patentes, pela autoridade governamental competente, por razões de "interesse público e, em particular, de segurança nacional, alimentação, saúde ou para desenvolver outros setores vitais da economia nacional". O licenciado seria organismo estatal ou terceiras pessoas autorizadas pelo Governo (art. 156). 
Penso que as legislações nacionais deveriam criar um regime alternativo, compreendendo as atuais patentes e os certificados de invenção. Estes últimos atribuíram ao titular de uma invenção registrada, o direito não-exclusivo de sua exploração durante tempo limitado. Vale dizer que qualquer interessado teria direito a explorá-la, pagando regalias, cujo máximo percentual seria prefixado em decreto ou regulamento administrativo, de modo a evitar o abuso de poder econômico. E o titular do certificado teria a obrigação legal de prestar assistência técnica gratuita ao licenciado.

No Direito brasileiro, a licença compulsória não exclusiva somente existe por motivo de interesse público, para a exploração de privilégio em desuso, ou cuja exploração efetiva não atenda à demanda do mercado (Cód. Propriedade Industrial art. 33, $\S 1^{\circ}$ ). Passados mais de dez anos de promulgação do vigente Código de Propriedade Industrial, o INPI deferiu um único caso de licença desse tipo; o que demonstra a inefetividade do instituto, ou o surpreendente grau, de utilização de privilégios industriais pelos seus titulares.

Nenhuma razão relevante subsistiria para proibir o registro de certas criações industriais de grande interesse social; como as de medicamentos ou alimentos, sob a forma de certificados de invenção e não de patentes. De um lado, o monopólio seria preexcluído pelo regime jurídico desses certificados; de outro, o sistema atual de controle administrativo de preços reduz o risco de exploração econômica do consumidor.

Mais: invertendo totalmente os termos do problema, a partir da consideração de que a proteção às invenções não é mero capítulo do direito concorrencial, mas verdadeiro estímulo à difusão tecnológica, pode-se cogitar de impor o depósito no país, como certificado de invenção, das invenções farmacêuticas de empresas estrangeiras, ainda em exploração, como condição administrativa de sua instalação no Brasil.

$O$ pedido de registro sob a forma de patente poderia ser transformado pela autoridade administrativa em certificado de invenção, conforme as manifestações de interesse na sua utilização, recebidas por terceiros, após a publicação do pedido.

Por outro lado, não seria desarrazoado criar estímulos ao registro de certificados de invenção, em lugar de patentes como, por exemplo, a dedutibilidade a título de despesa operacional, para fins tributários, dos royalties pagos pela utilização desses certificados, pela sociedade controlada à controladora, no país ou no estrangeiro; bem como a possibilidade de remessa desses royalties para o exterior. Entre nós, como é sabido, essa dedução fiscal é vedada (Regulamento do Imposto sobre a Renda, art. 232, III e IV) e a remessa cambial também (Lei 4.131, de 1962, art. 14).

Para ambos os títulos, dever-se-ia exigir, como condição de registro, o chamado avanço tecnológico (inventive step, activité inventive), 
além da novidade e da possibilidade de utilização industrial. É o que se prevê na lei-modelo sobre invenções para países subdesenvolvidos (art. 115) e em várias legislações nacionais.

Outra medida que parece recomendável para estimular o investimento tecnológico em países subdesenvolvidos é ampliar o âmbito de aplicação dos atuais modelos de utilidade, transformando-os em autênticas patentes de melhoramento.

No Brasil, ao contrário do que sucede em matéria de patentes, a grande maioria dos requerentes de registro de modelos de utilidade é de domiciliados no país (90,9\% em 1980 e 76,2\% em 1981). Mas a aplicação desse privilégio limita-se, por lei, à "disposição ou forma nova obtida ou introduzida em objetos conhecdos, desde que se prestem a um trabalho ou uso prátco" (Cód. da Propriedade Industrial, art. 10). Não se vê por que esse aperfeiçoamento inventivo não poderia aplicar-se, também, por exemplo, a processos de produção, como sucede com as chamadas "racionalizações", "melhoramentos técnicos", ou "inovações", na legislações dos países da Europa Oriental. O alargamento do campo de incidência dos modelos de utilidade certamente compreenderia várias inovações que, hoje, estão na vala comum do know-how. $\mathrm{E}$ nunca é demais sublinhar que a publicidade, inerente ao sistema dos privilégios industriais, favorece a divulgação tecnológica, em contraposição ao regime do segredo, próprio do know-how.

A respeito dessa publicidade das invenções depositadas, no entanto, a função de divulgação tecnológica acha-se, hoje, comprometida pela crescente obscuridade das descrições apresentadas. Sem dúvida, esse mau resultado é, em parte, devido à complexidade da técnica contemporânea, nos setores mais avançados. Mas em grande parte, também, resulta do óbvio interesse das empresas em revelar ao público o mínimo possível do que constitui a essência do seu poder de dominação no mercado.

Nesse sentido, é muito recomendável a disposição contida no artigo 123 - (3) da lei-modelo da OMPI sobre invenções para países subdesenvolvidos, ao exigir que a descrição técnica constante do pedido de registro "revele a invenção de modo suficientemente claro e completo, para que ela possa ser apreciada e posta em execução por qualquer pessoa habitualmente perita no campo técnico, devendo, em particular, indicar a melhor maneira conhecida pelo requerente para a utilização da invenção" É óbvio que esta última exigência compreende o know-how especialmente ligado ao invento.

Outro elemento do sistema de privilégios industriais carente de aperfeiçoamento é a exigência de efetiva exploração dos inventos registrados. Essa imposição, é claro, prende-se ao regime tradicional de exclusividade de exploração, perdendo sentido em matéria de certificados de invenção com direito não exclusivo de explorar, como sugerido acima. Mas o problema persiste, na medida em que perdurar o sistema clássico dos privilégios industriais. 
Alguns países latino-americanos - Colômbia, Peru, Equador e México - passaram recentemente a seguir a orientação pioneira de nosso país, de não considerar a importação dos produtos patenteados como forma de exploração efetiva da patente no país (Cód. Propriedade Industrial, art. $33, \S 1^{\text {\%) }}$.

Além disso, parece conveniente abandonar o sistema da Convenção de Paris, em que somente se admite o cancelamento de patentes por não-uso, quando a concessão de licenças obrigatórias não tenha sido suficiente para prevenir os abusos (art. 5\%, A, 3). Segundo informa o nosso INPI, até hoje nunca se concedeu em nosso país uma licença obrigatória de exploração por não-uso de patentes, já tendo havido casos de cancelamento por caducidade, o que demonstra a ineficiência daquele remédio para prevenir o abuso por omissão dos titulares de patentes.

Sugeriria, ainda, fossem encurtados de metade os prazos estabelecidos em nosso Código da Propriedade Industrial (art. 49) para a caducidade do privilégio, pela sua não-exploração efetiva.

\section{B - Contratos de know-how:}

A situação atual, nessa matéria, é das mais insatisfatórias.

Tratando-se de know-how puro, a preservação da posição concorrencial das empresas não provém de um registro público da inovação tecnológica, como no caso dos privilégios industriais, mas da estrita manutenção do segredo. Por conseguinte, as informações técnicas cuja prestação é negociada restringem-se, como é obvio, aos campos em que não existe possibilidade de concorrência, entre as partes contratantes. Daí resulta que a qualidade da tecnologia eventualmente transferível por via de contratos de know-how, do mundo industrializado para as regiões subdesenvolvidas do planeta, é geralmente de nível inferior. A empresa prestadora de know-how consente em transferir à receptora a tecnologia ultrapassada, de que já não se serve mais, o que pode ter algum interesse para as nações proletárias do "Quarto Mundo", mas que não atende às necessidades dos subdesenvolvidos em processo de industrialização. Ou, então, a empresa estrangeira instala-se no país subdesenvolvido, utilizando diretamente, ou por meio de controlada, a experiência técnica mais avançada, de que dispõe.

Fora desse dilema, há apenas uma estreita faixa a ser aproveitada do mundo industrializado: é a das empresas médias, não concorrentes das localizadas em países subdesenvolvidos, e que têm interesse em obter receita com a exportação de tecnologia de alta qualidade. É óbvio que ao aproveitamento dessa reduzida possibilidade acorrem todos os empresários avisados do Terceiro Mundo. Como orientar, então, a atividade empresarial nesse campo, em busca do melhor interesse nacional? 
O princípio cardeal da política econômica das nações subdesenvolvidas, nesse setor, deveria ser a máxima difusão tecnológica possível, de forma a criar obstáculos ao processo de natural concentração de poder econômico pelo monopólio da experiência técnica acumulada.

Sem dúvida, a proibição das cláusulas restritivas em contratos de transferência de tecnologia procura evitar esse efeito de abuso de posição dominante. Mas embora universalmente aplicada, essa proibição não tem se revelado, por si só, eficaz para produzir o desejado efeito de difusão tecnológica, no país receptor de know-how.

$E$ certamente indispensável enfrentar $o$ falso princípio da igualdade dos agentes econômicos no mercado e estabelecer a distinção básica dos contratos de transferência de tecnologia entre empresas pertencentes, ou não, ao mesmo grupo econômico, definido este em razão do controle societário efetivo. Nos contratos intragrupais, não existe a menor probalidade de difusão da experiência técnica no mercado, a não ser por violações esporádicas do segredo empresarial, o que não é, certamente, uma solução aceitável.

Å luz desse critério distintivo fundamental, não parece justificável, sob o estrito aspecto da política tecnológica, que o nosso Instituto Nacional de Propriedade Industrial acumule exigências para a averbação de contratos de know-how (fornecimento de tecnologia industrial, cooperação técnico-industrial e serviços técnicos especializados, segundo a classificação do Ato Normativo $n^{\circ} 15$ ), quando a empresa receptora não é controlada pela prestadora dos conhecimentos técnicos nem esta emprega os técnicos prestadores de serviço. Sem dúvida, não são desprezíveis os interesses fiscais ou cambiais em causa; mas, certamente, o INPI não é nem pode ser o órgão encarregado de zelar pela sua preservação. E se o conflito entre esses diversos interesses públicos se revela, em certa medida, insuprimível, compete aos responsáveis pela política econômica global do país (os quais, ao que parece, foram secretamente seqüestrados do cenário nacional) estabelecer opções e definir diretrizes, atendendo ao fato de que toda política implica o estabelecimento de uma hierarquia de interesses.

Ainda nessa mesma linha de raciocínio, não se percebe por que, a não ser na ótica vesga de um capitalismo retrógrado, falsamente nacionalista, as nossas autoridades públicas tendem a desfavorecer a importação de pessoal técnico especializado, desvinculado da importação de capitais. $\hat{\mathbf{E}}$ de se imaginar que a obsessão cambial atingiu até mesmo o nobre mercado da matéria cinzenta: o Governo brasileiro estimula a expatriação de técnicos brasileiros e dificulta o recrutamento de estrangeiros. Quando esses contratos de "serviços técnicos especializados" são celebrados dentro de um mesmo grupo, nacional ou multinacional, ainda se entende que a autoridade administrativa os examine rigorosamente. Mas fora dessa hipótese, tudo deveria ser feito para incentivar os empresários, aqui domiciliados, a privilegiar a prestação de trabalho, em relação à simples importação de capitaị ou, o que é pior, à alienação do controle empresarial. 
Quanto à colaboração tecnológica entre empresas pertencentes ao mesmo grupo econômico, admitindo-se, como me parece evidente, que eles não propiciam nenhuma difusão tecnológica no mercado, talvez se pudesse pensar numa alternativa à rigidez atual (razoavelmente justificável) em matéria tributária e de transferência de divisas. Ampliando os termos de uma sugestão feita em 1979 pela Comissão Mista Teuto-Brasileira de Cooperação Econômica, imaginaria a possibilidade de se admitir a dedutibilidade fiscal e a remessa cambial das quantias pagas por empresa controlada à sua controladora no exterior, a título de assistência técnica, desde que a empresa receptora do know-how se obrigasse a entregar quantia equivalente a institutos de pesquisa tecnológica indicados pelas autoridades governamentais e a admitir o estágio de técnicos desses institutos em suas fábricas e laboratórios de pesquisa.

\section{CONCLUSÃO GERAL: Ultrapassar as fronteiras do direito industrial, na transferência de tecnologia}

Concluindo, desejaria retomar a advertência feita desde a abertura destas considerações e relembrar que as sugestões aqui apresentadas constituem o aperfeiçoamento de um sistema forçosamente limitado, em sua capacidade de servir de veículo de transferência tecnológica, do mundo industrializado para as nações proletárias. É preciso, afinal, reconhecer e proclamar a evidência: em regime de livre concorrência entre unidades econômicas que obedecem à lei do lucro máximo, a desigualdade é sempre mais reforçada e acaba anulando a liberdade econômica, em nome da qual se erigiu o sistema. As relações empresariais, no mercado mundial, são relações de poder, com fins egoistas; e o poder econômico é, hoje, sempre mais função da acumulação tecnológica. Ora, na lógica do poder, ninguém se despoja de sua supremacia voluntariamente.

Por outro lado, as nações subdesenvolvidas já não podem ser mantidas na ilusão de que, um dia, chegarão a igualar o nível de vida dos países opulentos. Seria isto repetir, de forma tragicamente coletiva, a velha fábula da rã e do boi. Basta àquelas nações limitar seu projeto coletivo a uma erradicação da miséria generalizada e do desperdício luxuoso das camadas dominantes - o que já é tarefa ingente, envolvendo gerações. Para realizá-la, o domínio tecnológico na produção é obviamente necessário. Mas ele deve ser alcançado segundo os objetivos próprios dos países pobres, e não de acordo com os interesses permanentemente hegemônicos das nações industrialmente desenvolvidas.

Isto supõe uma transformação radical, tanto no plano da organização interna dos países subdesenvolvidos, quanto no da estrutura das relações internacionais, o que ultrapassa largamente os estreitos limites do chamado direito industrial. 
No plano interno, o processo de contínua criação e absorção de tecnologia somente pode assentar-se no desenvolvimento endógeno do saber científico, que não pode ser levado a cabo sem uma larga base de instrução, a ser propiciada pela educação popular. Esta, por sua vez, implica a alteração do atual sistema de concentração do poder e da riqueza numa minoria da população.

No plano internacional, o estabelecimento de relações menos desiguais passa pela necessária união das nações subdesenvolvidas em defesa de suas riquezas e de seus mercados, de forma a superar o isolamento submisso na carência econômica. A associação dos países subdesenvolvidos, por meio de acordos regionais ou setoriais de recíproca defesa econômica e coordenação de atividades, perante as nações poderosas e as empresas multinacionais, é hoje tão indispensável para a reconstrução do direito internacional quanto foi, no passado, a sindicalização operária, para o surgimento de um verdadeiro direito do trabalho. 